\section{LOS ESPACIOS DEL ARTE: EL DISEÑO DEL PANEL Y LA ARTICULACIÓN DEL PAISAJE EN EL ARTE RUPESTRE GALLEGO}

\author{
THE SPACES OF ART: THE DESIGN \\ OF PANEL AND THE ARTICULATION \\ OF LANDSCAPE IN GALICIAN \\ ROCK ART
}

\section{MANUEL SANTOS ESTÉVEZ}

\section{A mis padres.}

"Si quiere bailar y no hacer

windsurf, súbase a un canto rodao".

El Gran Salto a la Fama.

Los Tres Sudamaricones.

\section{RESUMEN}

Se estudian los grabados rupestres al aire libre como un recurso para construir el espacio de los paneles y como forma de articular el paisaje. En los paneles y en las estaciones de arte rupestre se definen una serie de modelos que estructuran el espacio del arte. Se resalta también la importancia del emplazamiento como elemento fundamental para comprender el arte rupestre al aire libre. Así en el estudio de los paneles, los motivos, probablemente alusivos a lo masculino: armas, escenas de equitación y ciervos macho aparecen en la parte superior del panel. En un segundo nivel de análisis, en las estaciones son estos mismos motivos los que aparecen en emplazamientos más destacados en el paisaje. También se estudian los llamados Sistemas de Estaciones, formados por grupos de petroglifos que delimitan territorios en la Edad del Bronce.

\section{ABSTRACT}

This paper analyses open air rock engravings both as resources to create space in panels and as mechanisms for

(*) Grupo de Investigación en Arqueoloxía da Paisaxe. Instituto de Investigacións Tecnolóxicas. Universidade de Santiago de Compostela. Dirección postal: Edificio Monte da Condesa-USCCampus Sur. 15706 Santiago. Correo electrónico: pharpa@usc.es.

El artículo fue remitido en su versión final el 29-VI-98. landscape construction. A series of models are defined, both in panels and in panel groups, that structure the space of art. We also highlight the importance of placement as an essential element in the understanding of open air rock art. Through the study of panels, we have discovered that the motifs apparently referring to the male-weapons, riding scenes and stags-are placed at the top of panels. At a second level of analysis, the groups of engraved rocks, those motifs appear on rocks located at points which stand out in the landscape. Finally we find a third level of analysis, the so called Systems of Groups of Engraved Rocks, formed by groups of petroglyphs delimiting Bronze Age territories.

Palabras clave: Arte rupestre. Territorialidad. Arqueología del Paisaje. Petroglifos. Edad del Bronce. Galicia.

Keywords: Rock art. Territoriality. Landscape Archaeology. Petroglyphs. Bronze Age. Galicia.

\section{INTRODUCCIÓN}

La piedra como metáfora de la tierra y el grabado como representación de la cultura ilustran de forma elocuente una de las finalidades del arte ru- 
pestre al aire libre con independencia de la época y el lugar al que nos refiramos.

Esta es la base de la que parte nuestro concepto de arte rupestre al aire libre. Un arte en el que, a diferencia del arte mueble, es el observador el que se mueve para contemplarlo. Para ello los grabados han de situarse en lugares frecuentados por los potenciales observadores: caminos, lugares de reunión, etc., en definitiva lugares de especial significación social.

El trabajo se desarrolló en tres zonas de arte rupestre pertenecientes a la Edad del Bronce y localizadas en la provincia de Pontevedra y una cuarta de cronología indeterminada situada en el lugar de A Ferradura (Ourense) (Fig. 1). Las estaciones pertenecientes a la Edad del Bronce serán estudiadas a tres niveles distintos. En el primero están los sistemas de estaciones, los petroglifos se vinculan a los accesos a las sierras sirviendo de delimitadores de posibles territorios. Esta idea es compatible con el concepto de paisaje parcelado empleado por $\mathrm{F}$. Criado (1994) para describir el tipo de paisaje en la Edad del Bronce.

Este patrón de distribución de los motivos también es observable en un segundo nivel: las estaciones.

En el tercer nivel, el petroglifo (1), estudiaremos una serie de paneles que por la complejidad y variedad de motivos nos pueden ayudar a ilustrar su patrón de distribución dentro de la roca. Para facilitar el estudio, utilizaremos un sistema de representación que sintetiza la distribución de los motivos en los paneles. Para ello asignaremos una letra a cada uno de los diseños representados en los petroglifos, de acuerdo con las siguientes correspondencias:
A Combinaciones circulares.
B Cérvidos.
C Cuadrúpedos indeterminados o sin corna- menta.
D Antropomorfos.
E Escenas de equitación.
F Armas.

Para representar esquemáticamente la distribución de los motivos, situaremos a la izquierda los motivos de la parte superior del panel y a la derecha los de la parte inferior. De este modo, si tenemos un panel con una combinación circular, un cérvido

(1) En la literatura arqueológica sobre arte rupestre, se aplica generalmente el término petroglifo para hacer referencia al grabado. En el presente trabajo se emplea este concepto refiriéndose al grabado y al soporte en su conjunto.

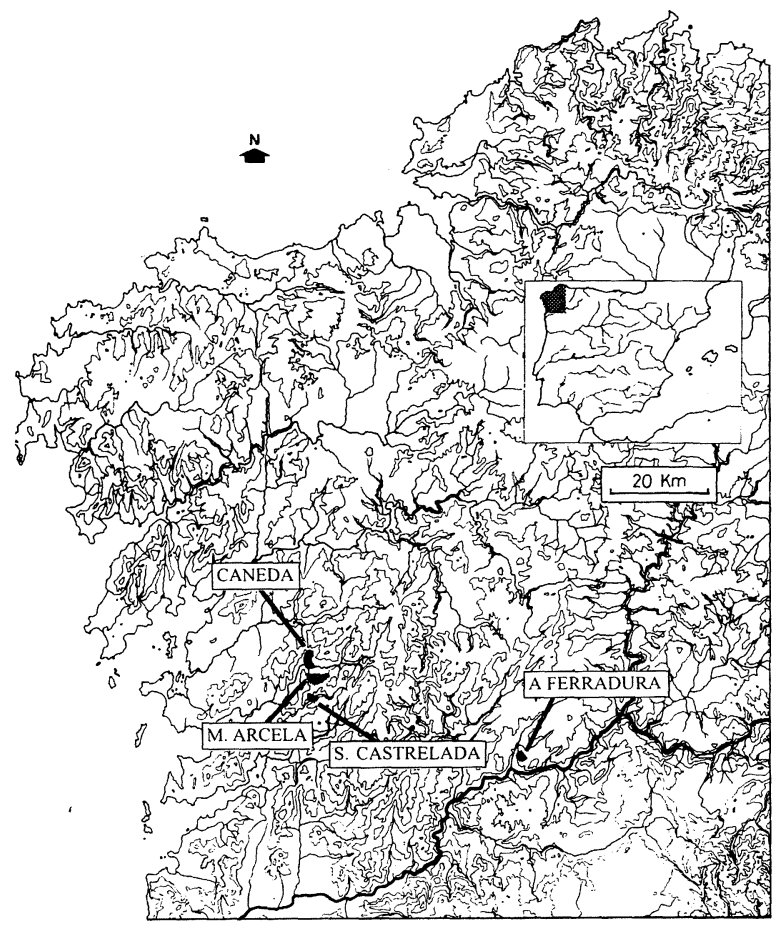

Fig. 1. Localización de las zonas estudiadas.

debajo y un antropomorfo debajo de éste, el esquema sería: ABD. Dos motivos a la misma altura, se indicarán como: A-B.

\section{EL ESPACIO DE LOS SISTEMAS DE ESTACIONES}

Denominamos sistema de estaciones a los conjuntos de petroglifos asociados a una misma unidad fisiográfica, generalmente una sierra. En estos sistemas los petroglifos se disponen rodeando la sierra por su base y concentrándose en el inicio de los accesos al monte.

\section{Sistema de estaciones de Monte Arcela}

Monte Arcela se sitúa al norte del término municipal de Cotobade entre los valles de los ríos Lérez y Almofrei (Fig. 2). La prospección y estudio de la zona fue realizada durante la catalogación arqueológica del término municipal (2). Las publica-

(2) En concreto se trata del proyecto de Catalogación e Delimitación Planimétrica dos Xacementos Arqueolóxicos do Concello de Cotobade, con la Dirección Xeral do Patrimonio Cultural (Consellería de Comunicación Social) como promotor y realizado por J.I. Vilaseco Vázquez y el que suscribe este artículo. 


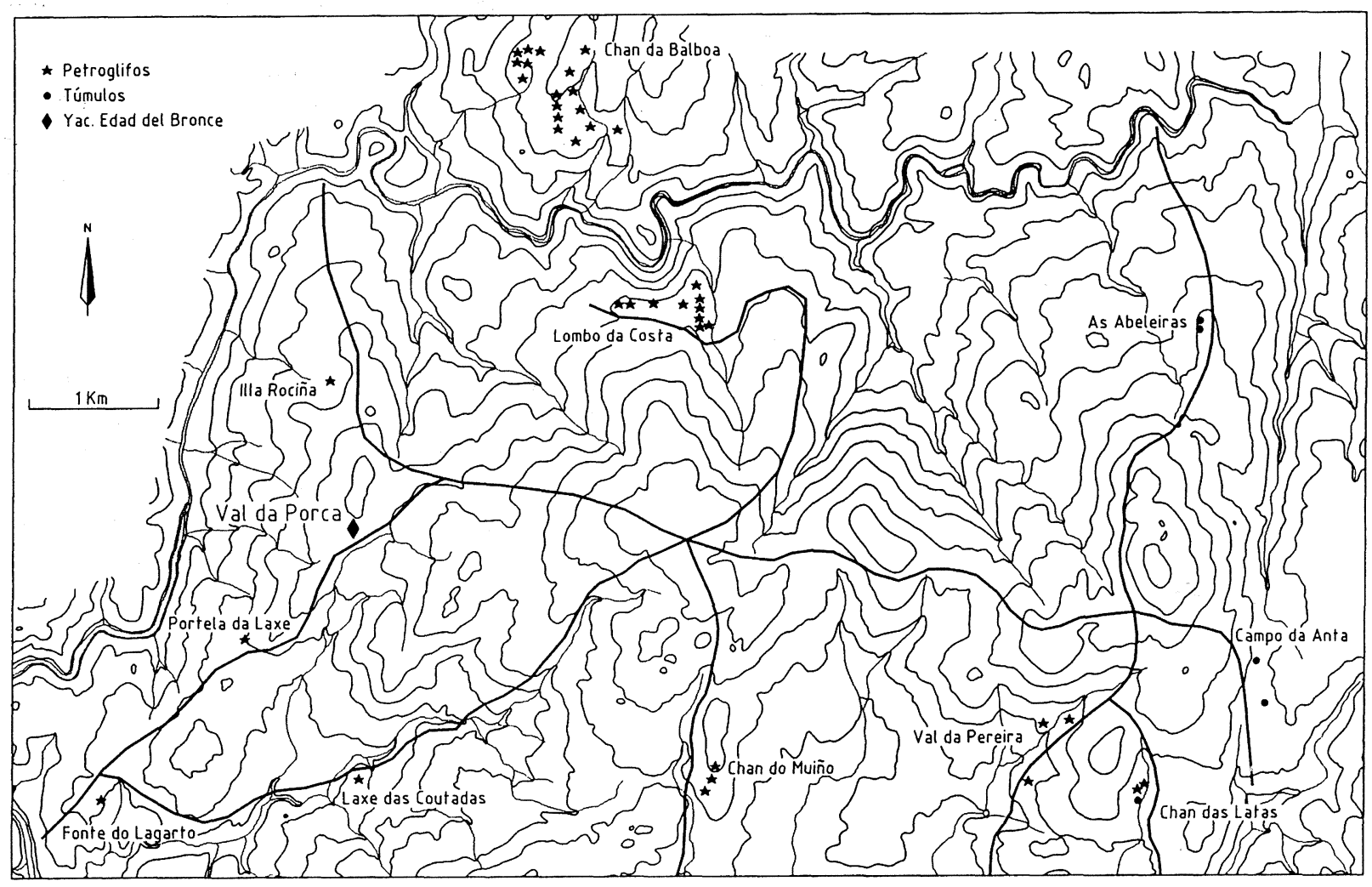

Fig. 2. Zona de Monte Arcela. Distribución de los petroglifos, túmulos y el asentamiento de Val da Porca. Los yacimientos aparecen asociados a las líneas de tránsito y delimitando la sierra de Monte Arcela.

ciones sobre el municipio se deben a Sobrino (1935), Filgueira y García (1953), Fraguas (1955) y García y Peña (1981).

Las estaciones de esta zona son las siguientes:

Lombo da Costa. Se sitúa en torno a una rellano de relieve alomado. Este rellano sirve también de lugar de paso entre las escarpadas laderas del monte y el cañón del río.

Los paneles más complejos son los de Laxe do Cuco (Fig. 3-3), una de las superficies de Lombo da Costa (Fig. 3-1) y Laxe das Rodas (Fig. 4-3). Durante la prospección se localizaron algo más de veinte rocas grabadas, lo que la convierte en la estación de mayor envergadura: encontramos aquí más de la mitad de los petroglifos de Monte Arcela.

Además de esta gran estación se localizan pequeños grupos de rocas caracterizadas básicamente por poseer un número muy inferior de grabados, un repertorio tipológico más reducido y un emplazamiento distinto, es decir, generalmente en zonas de paso o de acceso al monte, pero no en rellanos a media ladera como era el caso anterior.
Illa Rociña y Portela da Laxe. Illa Rociña tiene grabada una combinación circular. Se encuentra en una ladera por la que discurre una línea de tránsito que asciende al yacimiento de la Edad del Bronce de Val da Porca localizado durante el Seguimiento Arqueológico de las obras de construcción del Oleoducto Coruña-Vigo (3). Portela da Laxe posee combinaciones circulares, figuras cuadrangulares, esvásticas y alguna cruz inscrita. Como su nombre indica, se encuentra en unaportela o acceso al monte que al igual que en el caso anterior conduce a Val da Porca.

Fonte do Lagarto. Con combinaciones circulares y un cuadrúpedo. $\mathrm{Al}$ igual que los anteriores estaciones se sitúa en un punto de arranque de la subida al monte (Fig. 4-2).

(3) Una documentación más amplia en la tesis de licenciatura de Prieto Martínez (1996): Estudio de la cerámica del II milenio a.C. de la Sierra del Bocelo y el occidente gallego. Universidade de Santiago de Compostela, Departamento Historia I y en la Tesis doctoral de Méndez Fernández (1998): División social y construcción culturall del paisaje durante la Edad del Bronce en Galicia. Universidade de Santiago de Compostela. Departamento de Historia I. 

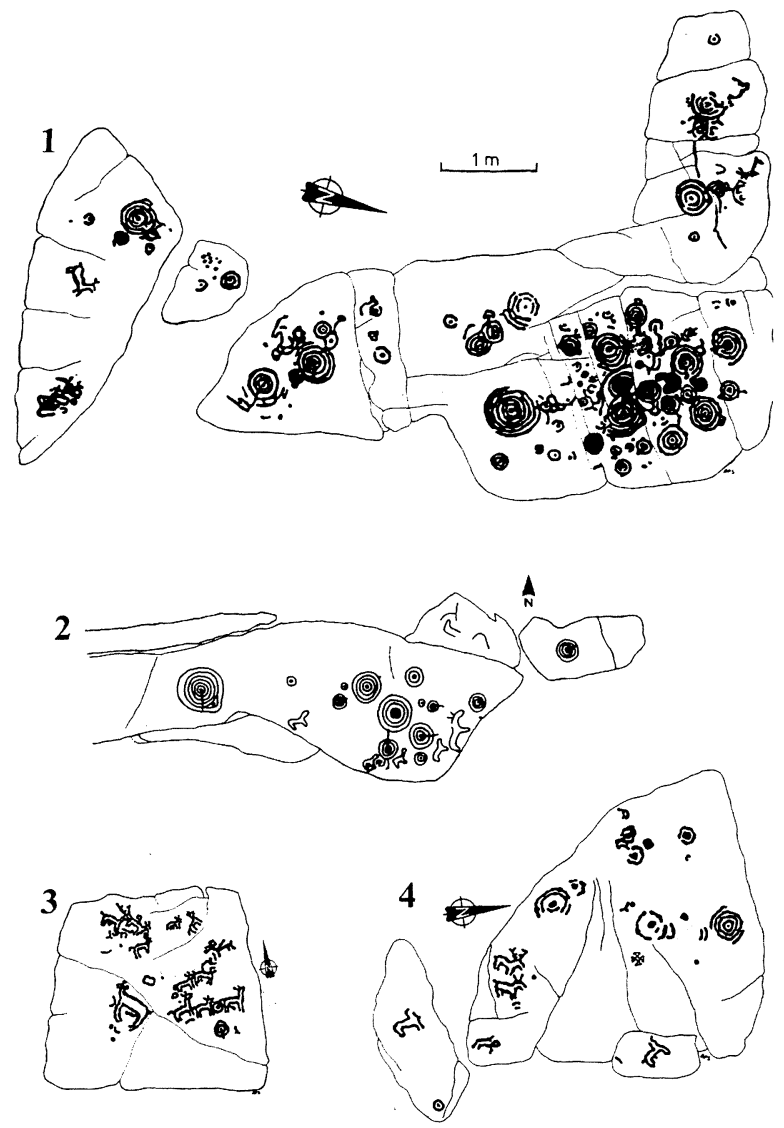

Fig. 3. 1. Lombo da Costa XV. 2. Laxe das Coutadas. 3. Laxe do Cuco. 4. Lombo da Costa V (Pontevedra).

Pedra das Coutadas. Los motivos grabados son un grupo de combinaciones circulares y un grupo de cuadrúpedos. Se sitúa en un punto de paso de la misma línea de tránsito que partía de Fonte do Lagarto (Fig. 3-2).

Chan do Muiño. Consta de tres pequeñas rocas con un círculo simple cada una. Se sitúan en un rellano en uno de los accesos a la sierra.

Val da Pereira. Está formada por tres rocas grabadas, el panel más sencillo con tres cazoletas y el más complejo con un buen número de combinaciones circulares. Dentro de la estación hemos de destacar por su complejidad el petroglifo de Pedra das Cuadas dos Mouros.

Chan das Latas. Se trata de dos rocas con varias combinaciones circulares cada una. Se sitúa muy próxima a un túmulo de pequeñas dimensiones. Nos encontramos entonces con dos tipos de yacimientos posiblemente relacionados entre sí y asociados ambos a una braña (turbera topogénica de no muy amplia extensión en las que es posible disponer de pasto fresco incluso en épocas de sequía estival).

La disparidad en la distribución de los petroglifos podría interpretarse como la expresión de una categorización de los distintos lugares. Si analizamos el emplazamiento de las estaciones, podemos observar que Lombo da Costa se encuentra en un lugar con una serie de características morfológicas y de emplazamiento que la diferencia del resto.

Lombo da Costa se sitúa en un rellano a media ladera, alrededor del cual se disponen los petroglifos y desde el que se divisa una amplia panorámica, especialmente el área de Caneda y todo el valle de Campo Lameiro. En cambio, en el resto de las estaciones, situadas unas en rellanos, otras en zona de braña y otras en laderas, aunque en ocasiones poseen amplio dominio visual sobre el entorno, ninguna de ellas reúne todas las características de visibilidad, visibilización, tamaño y complejidad de Lombo da Costa.

Como hipótesis de trabajo podríamos plantear la
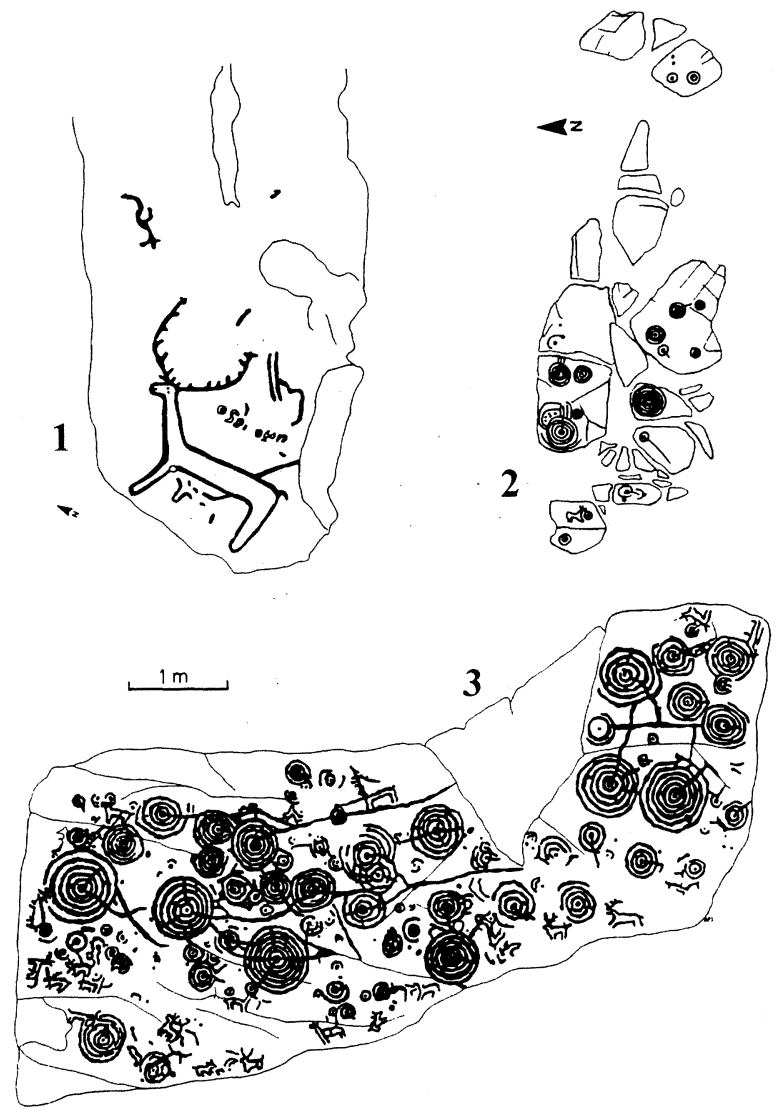

Fig. 4. 1. Campo de Cuñas. 2. Fonte do Lagarto. 3. Laxe das Rodas (Pontevedra). 


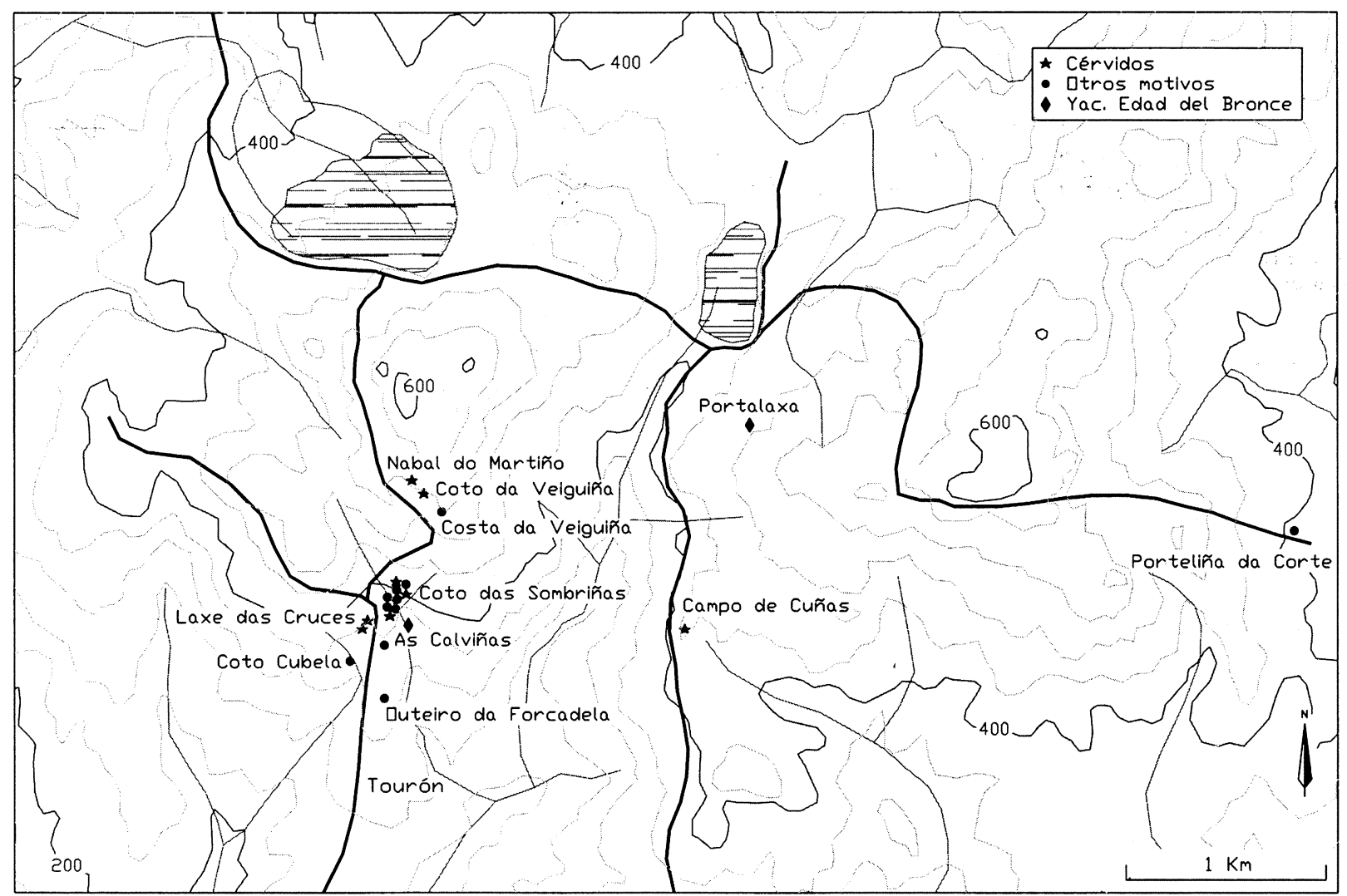

Fig. 5. Distribución de las estaciones de Serra Castrelada. Los petroglifos aparecen asociados a líneas de tránsito y delimitando la sierra.

existencia de dos tipos de lugares diferenciables por la mayor o menor concentración de petroglifos, por la mayor o menor complejidad de sus paneles, y por el tipo de emplazamiento.

Podemos comprobar como todos los accesos tradicionales al monte están señalados por alguna de las estaciones a excepción de las dos más orientales en las que se sitúan grupos de túmulos con un emplazamiento con respecto a las vías de tránsito idénticas a la de los petroglifos (Fig. 2). Independientemente de la sincronía o diacronía de ambos tipos de monumentos, parece existir cierta convivencia e incluso una posible asociación que se concreta en la proximidad entre la mámoa o túmulo y los petroglifos de Chan das Latas.

De forma genérica, podemos resumir el emplazamiento del conjunto de petroglifos de Monte Arcela como un sistema de estaciones que demarcan los accesos a los altiplanos de la sierra donde se localizan los poblados de la Edad del Bronce. Aunque sólo contamos con un asentamiento en la zona, estudios precedentes en otras áreas como Serra do
Bocelo, Amoedo, etc. (Méndez 1991, 1994) así lo sugieren. En definitiva y como hipótesis, los petroglifos serían una expresión visible de la existencia y demarcación de un territorio.

\section{Sistema de estaciones de Serra Castrelada}

Las primeras referencias sobre la existencia de petroglifos en la parroquia de Tourón (Ponte Caldelas) son de Sobrino (1935), el primer inventario de Peña (1986) y después de Santos (1996).

La estación de Tourón se encuentra al pie del Monte Pedamúa que forma parte de la unidad fisiográfica conocida como Serra Castrelada (Fig. 5). Durante los trabajos de prospección y posteriormente seguimiento del gasoducto del noroeste fueron localizados los petroglifos de Campo de Cuñas y Porteliña da Corte (4) .

(4) Ambos trabajos realizados por el Grupo de Investigación en Arqueoloxía da Paisaxe de la Universidade de Santiago de Compostela. 
Tourón. Es la más compleja del conjunto. Su emplazamiento le permite tener una amplia visibilidad a larga distancia, por hallarse en un lugar relativamente elevado, en el extremo de una falla que en su tramo final es seguida por el río Tea hasta su desembocadura en Salvaterra do Miño en la frontera con Portugal.

El área que nos ocupa se encuentra rodeada por petroglifos situados en las laderas que la delimitan. Las rocas grabadas están próximas a las principales líneas de tránsito que desde el valle ascienden a la sierra. Son los petroglifos de Coto das Sombriñas (Fig. 6-2,3 y 4), Outeiro da Forcadela, Coto Cubela, Laxe das Cruces (Fig. 6-1), Costa da Veiguiña, Coto da Veiguiña y Nabal do Martiño (Fig. 6-5). La estación se sitúa en un rellano a media ladera donde se encuentran los dos petroglifos más complejos de la comarca y se concentran alrededor de una veintena de rocas grabadas, lo cual supone más del $75 \%$ de los petroglifos de toda la sierra.

Campo de Cuñas. El petroglifo se encuentra en un rellano situado al este de la estación de Tourón y al pie de Serra Castrelada. En términos generales su emplazamiento es el mismo que el de los petroglifos descritos hasta el momento, que puede ser definida como una portela o punto de arranque de subida al monte. Se trata de un gran cérvido de dos metros de largo por dos metros de alto; bajo el que se encuentra un pequeño cuadrúpedo incompleto (Fig. 4-1). La figura de este cérvido recuerda a la del gran ciervo de Laxe das Cruces en Tourón.

Porteliña da Corte. Se encuentra en el municipio de Cotobade, en una de las entradas a la Serra Castrelada, concretamente al pie del monte. Se trata de un conjunto de grabados divididos en cinco rocas muy próximas entre sí. Además de algunas cruces, presenta un gran número de cazoletas, alrededor de veinte combinaciones circulares y un cuadrúpedo.

De nuevo volvemos a encontrar una clara diferencia entre una gran estación, como es la de Tourón, y otras dos que, aúnque formadas por un gran panel, carecen de la entidad de la estación principal.

Para completar este sistema de paisaje con petroglifos, hay que añadir que durante el seguimiento arqueológico de las obras de construcción del ramal Pontevedra-Ourense del proyecto de gasificación de Galicia, fue encontrada una fosa en la zanja de obra con materiales cerámicos pertenecientes a la Edad del Bronce. Esta fosa se sitúa en un lugar llano,

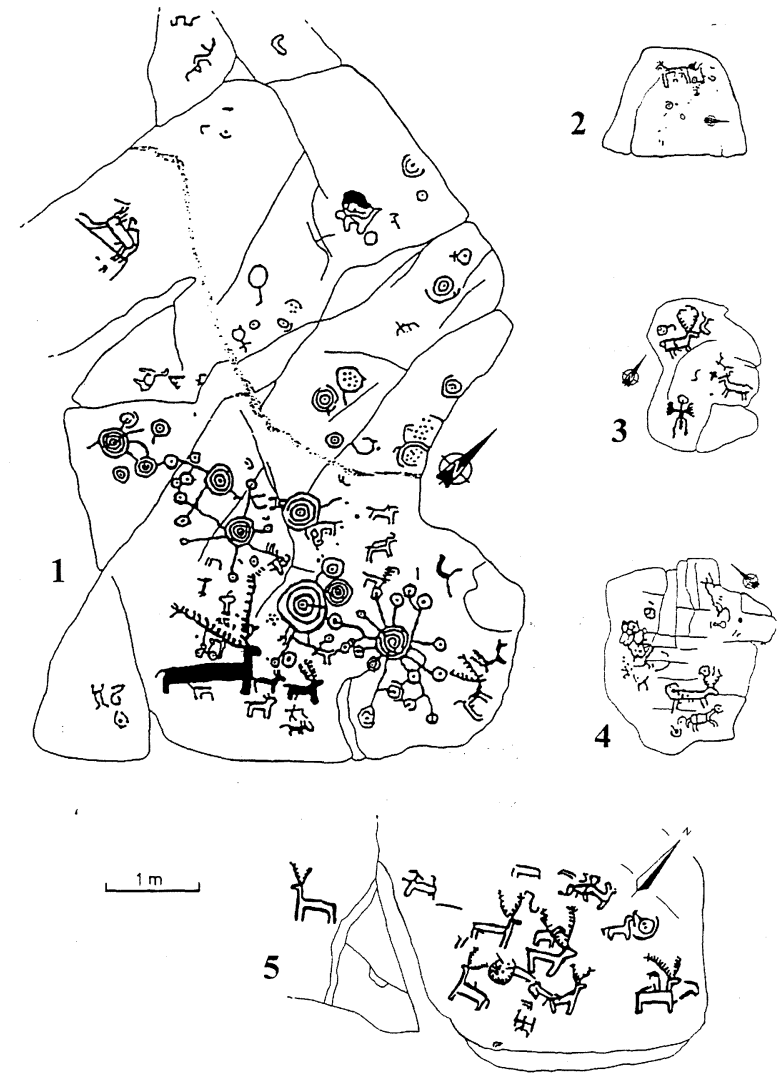

Fig. 6. 1. Laxe das Cruces. 2. Coto das Sombriñas V. 3. Coto das Sombiñas IX. 4. Coto das Sombriñas VI. 5. Nabal do Martiño (Pontevedra).

conocido como Chan do Touro o Portalaxa, ubicado en las zona alta del monte en un emplazamiento análogo al de Val da Porca en Monte Arcela.

\section{EL ESPACIO INTERNO DE LAS ESTACIONES}

Para el estudio de la distribución de los rocas grabadas dentro de cada estación tendremos en cuenta tres características. La primera es el grado de complejidad, que define dos categorías de petroglifos: monumentales y sencillos. La segunda es el motivo de los paneles, estudiaremos en qué contexto se hallan los motivos más representativos. La tercera es la orientación de las figuras zoomorfas.

Antes de proceder al análisis del espacio en las estaciones definiremos qué son los petroglifos monumentales y en qué se diferencian de los petroglifos sencillos. 


\section{Petroglifos monumentales}

1. Están en rocas de gran tamaño, que albergan un gran número de grabados.

2. Las rocas destacan sobre el terreno por su tamaño, emplazamiento y en ocasiones por su forma.

3. Su carácter monumental hace que en ocasiones den nombre al lugar en el que se encuentran, lo cual significa que éste es utilizado con frecuencia como punto de referencia (5).

4. Los grabados se sitúan muchas veces en paneles inclinados, lo que facilita su visibilización desde una mayor distancia.

5. Poseen paneles complejos con gran variedad de motivos. Pueden presentar grabados de armas, grandes motivos circulares y motivos poco frecuentes como idoliformes, laberintoides, etc.

6. El panel ocupa la totalidad o la mayor parte del campo visual del observador

Ejemplos de petroglifos monumentales dentro de las áreas estudiadas son Pedra das Ferraduras, los petroglifos principales de Chan da Lagoa, Laxe das Rodas, Laxe das Cruces o Naval do Martiño.

\section{Petroglifos sencillos}

1. Suelen estar en rocas pequeñas, a ras del suelo y en superficies poco inclinadas.

2. Pueden situarse en lugares de paso, de entrada a las zonas de monte o en torno a pequeñas cubetas.

3. Los paneles son sencillos y con un reducido repertorio de motivos.

4. Los motivos suelen ser de pequeño tamaño.

5. Los paneles no ocupan todo el campo visual.

\section{Estación de Caneda}

Las principales publicaciones son las de Álvarez y Velasco (1979), Álvarez (1985) y Bradley et alii (1994 y 1995) (6)

Encontramos aquí la mayor concentración de arte rupestre de la comarca. Entre los municipios de Cotobade y Campo Lameiro (Pontevedra) próxima a las Rías Baixas, situada sobre el cañón del Lérez

(5) Además son estos petroglifos los pocos que suelen contener referencias míticas en la Galicia tradicional.

(6) Nuestro artículo es deudor de este último trabajo, ya que sirvió de arranque para mis investigaciones en la zona al abrir una nueva perspectiva sobre la misma.

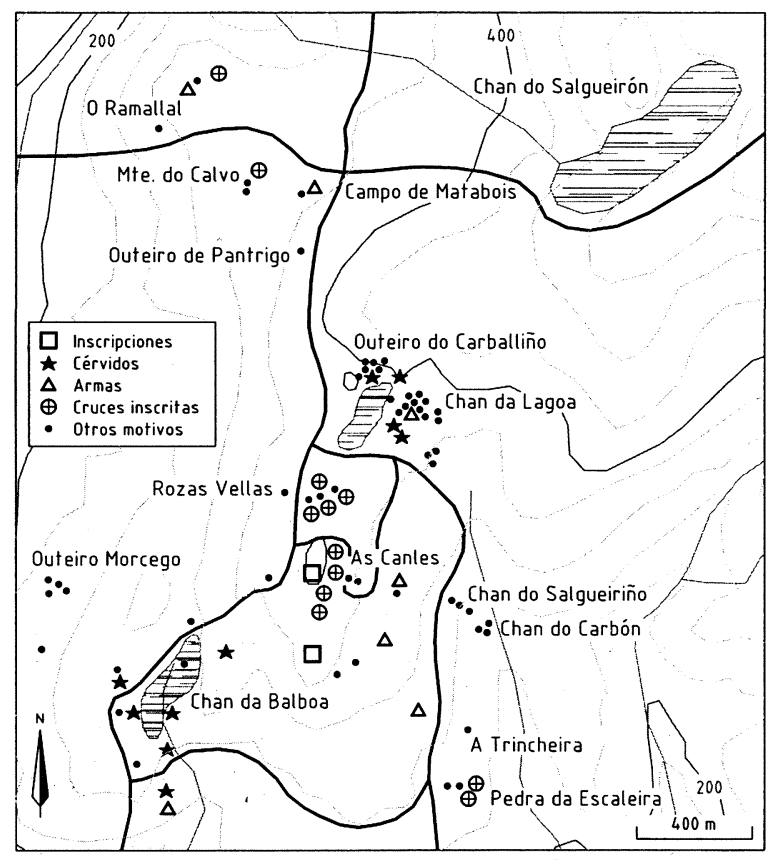

Fig. 7. Caneda. Distribución de los petroglifos según los motivos representados y de las vías de tránsito. Destaca la vinculación de las representaciones de cérvidos a las brañas de Chan da Balboa y Chan da Lagoa.

en una posición simétrica a Chan da Lagoa. Son frecuentes las pequeñas extensiones dedicadas a pasto, entre las que destacan las brañas. En Caneda tenemos tres brañas, en Fentáns en el denominado Chan de Balboa, otra en Chan da Lagoa y por último en Chan do Salgueirón cerca de la cima de la sierra (Fig. 7) (7).

En síntesis se emplazan en una zona llana a modo de escalón, con una amplia visibilidad sobre el entorno y en donde confluyen varias líneas de tránsito que la atraviesan.

Los conjuntos se agrupan por sectores. Cada uno de ellos comprende un conjunto de petroglifos próximos entre sí y vinculados a un sitio determinado.

Chan da Balboa. Se sitúa en los accesos a una amplia braña y en torno a ella. Este grupo se puede dividir en dos áreas, una situada en torno a la braña, con una gran variedad de motivos, donde se ubican los petroglifos más complejos, y otra al oeste, desde la que no se divisa esta braña, con combinaciones circulares y cazoletas. En el primer grupo,

(7) Preferimos emplear el término chan en lugar de llano, ya que se ajusta mejor al concepto al que nos referimos. Éste se podría definir como un llano de pequeña extensión situado generalmente en una zona de montaña. 


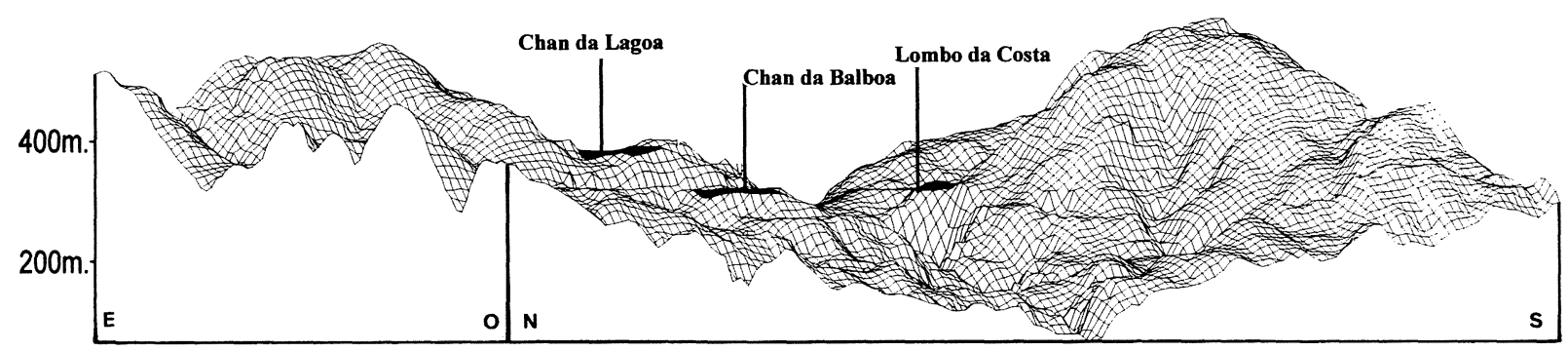

Fig. 8. Emplazamiento de las grandes estaciones de las zonas de Caneda y Monte Arcela en rellanos a media ladera y de amplia visibilidad sobre el entorno.

los grabados más destacables son Laxe das Ferraduras (Fig. 9-3), Coto do Rapadoiro (Fig. 9-1) y Laxe dos Cebros (Fig. 9-2).

Pedra da Escaleira y A Trincheira. Se localizan en la periferia de la estación. Consta de trece rocas, los motivos grabados son cruces inscritas, una espada, combinaciones circulares y cazoletas. La mayoría de los paneles son muy sencillos.

Chan do Carbón y Chan dos Salgueiriños. Se encuentra próximo a la vía de penetración desde la aldea de Parada que asciende hacia Chan da Lagoa y As Canles. Está formado por siete piedras con cazoletas y combinaciones circulares.

As Canles y Rozas Vellas. La mayoría de las rocas grabadas se encuentran en la ladera oriental del monte. Presenta un total de treinta y cinco piedras. Los petroglifos de este sector son muy sencillos, normalmente poseen dos o tres motivos: combinaciones circulares, cruces inscritas en círculos (Fig. 9-4), algún zoomorfo y armas. Existen dos inscripciones Outeiro do Gallo y Outeiro do Couto en las cimas de sendos outeiros (8) situados en la parte más alta del monte. En ambas rocas aparece la inscripción DIVI (9).

Chan da Lagoa y Outeiro do Carballiño. Se encuentra en el centro de la estación. Los petroglifos se disponen en torno a la braña que da nombre al lugar. El grupo está formado por unas veintidós rocas. En Chan da Lagoa se emplazan dos de las piedras grabadas de mayor complejidad de la estación, situadas precisamente en la entrada alchan. Ambos petroglifos tienen paneles muy similares (10) compuestos por un grupo de figuras laberintoides en el

(8) Cerro de pequeña extensión y de altura variable. En la zona que nos ocupa se caracteriza por las numerosas afloraciones graníticas existentes en su cima.

(9) En Santos et alii (1998) se analizan con detalle estas inscripciones y su contexto arqueológico.

(10) Es relativamente frecuente el hecho de que dos petroglifos situados muy próximos posean composiciones muy similares. Esto fuera ya observado en la estación de Tourón en los casos de Costa da Veiguiña y Coto da Veiguiña (Santos, 1996).

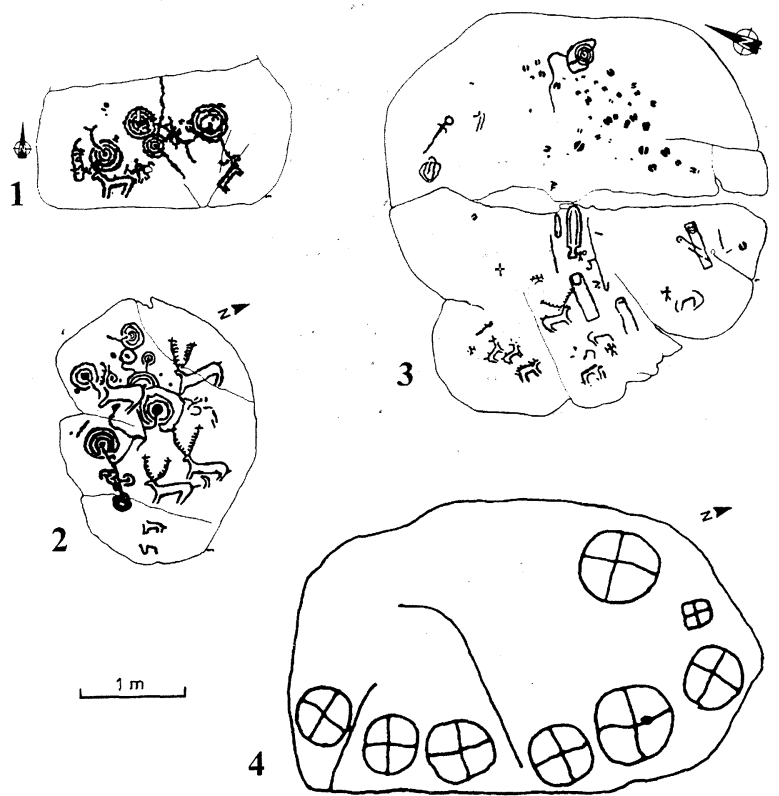

Fig. 9. 1. Coto do Rapadoiro. 2. Laxe dos Cebros. 3. Laxe das Ferraduras. 4. Petroglifo de As Canles con cruces inscritas (Pontevedra).

centro y numerosos cérvidos rodeándolas (Fig. 101 y 2). Los motivos del resto de las rocas son cazoletas, armas, combinaciones circulares, cuadrúpedos, idoliformes y huellas de ungulados.

Campo de Matabois y Outeiro do Pantrigo. Se encuentran en uno de los accesos principales de la estación. Se trata de un conjunto compuesto por un total de once rocas. Los motivos grabados son cazoletas de gran tamaño, combinaciones circulares, pseudolaberintos, paletas, huellas de ungulado, espadas, puñales e incluso cruces. Este conjunto es uno de los más complejos de la estación.

O Ramallal y Monte do Calvo. O Ramallal está formado por seis piedras, en general con paneles muy sencillos, a excepción del conjunto de once espadas de una de las rocas. En el resto de los petroglifos aparecen cuadrúpedos y combinaciones 

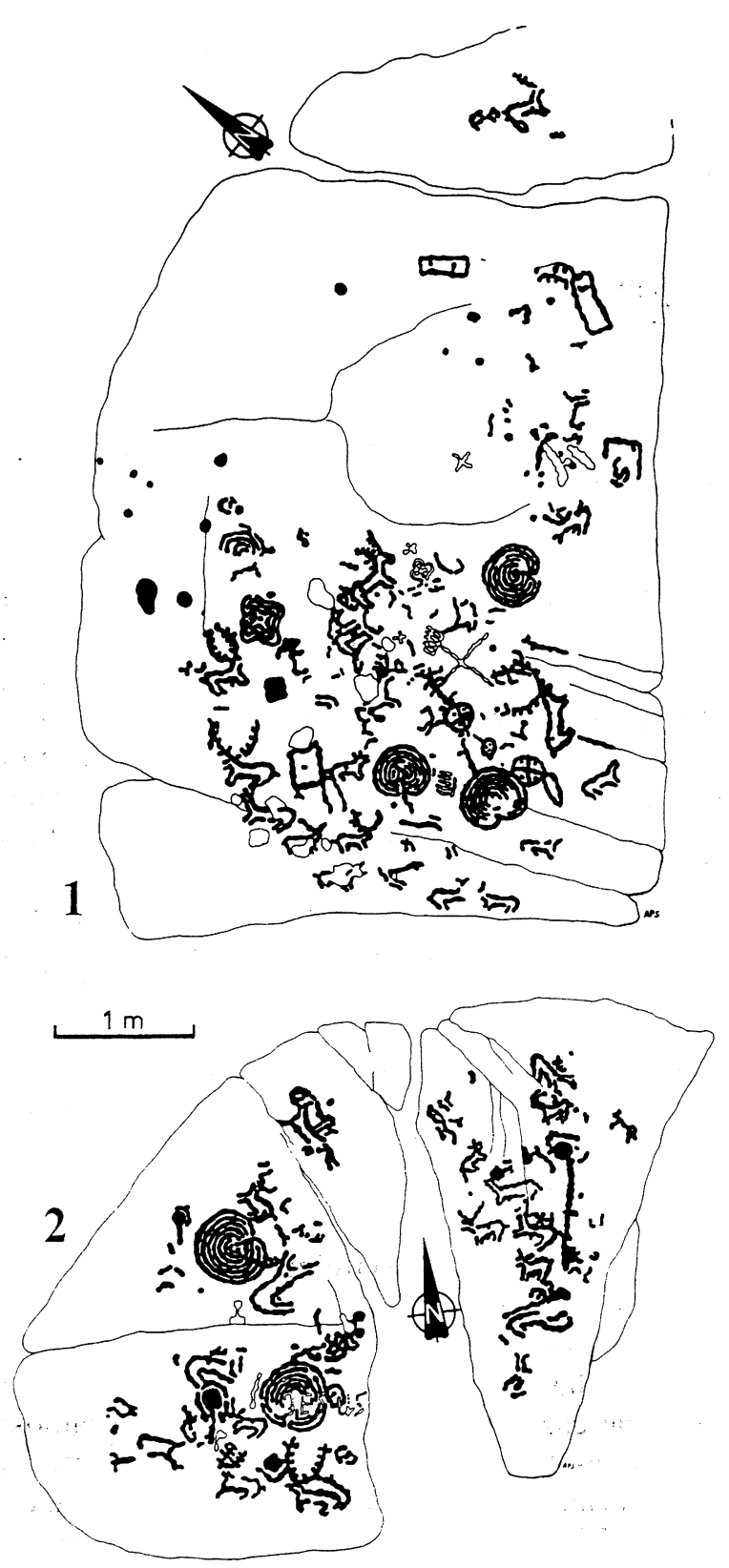

Fig. 10. 1 Chan da Lagoa I. 2 Chan da Lagoa II (Pontevedra).

circulares. Monte do Calvo es un conjuntó de dos grandes laxes situadas en la cima de sendos outeiros con reticulados, escaleriformes y cruces inscritas en círculos.

\section{Organización del espacio de la estación}

Si la práctica totalidad de los petroglifos se localizan en los rellanos a media ladera, es más con- cretamente en torno a los dos chans, Balboa y A Lagoa, donde se encuentra el mayor número y los paneles de mayor complejidad con la única excepción del conjunto de Campo de Matabois.

En resumen podemos definir tres elementos fundamentales del paisaje. En primer lugar tenemos los chans, asociados a brañas, en segundo lugar las líneas de tránsito que posibilitan el acceso a las mismas y que las intercomunican, y por último las entradas o portelas a la unidad fisiográfica en la que se encuentra la estación. Estos elementos generan un modelo en el que se individualizan: lugares centrales, accesos o caminos y entradas (11), que en el caso de la estación de Caneda se refleja del siguiente modo.

Los lugares centrales o chans son en concreto Chan da Lagoa y Chan da Balboa, que se caracterizan por ser pequeñas plataformas llanas situadas a media ladera con una amplia braña. Por lo tanto son aquellas brañas situadas en llanos con una amplia visibilidad las que albergan arte rupestre. Es aquí donde se sitúan la práctica totalidad de los cérvidos y la mayor parte de los petroglifos más complejos (Chan da Lagoa, Laxe dos Cebros y Laxe das Ferraduras). Es necesario resaltar el hecho de que la tercera gran braña, situada en Chan do Salgueirón, no posee en su entorno ningún petroglifo, aunque también hay que señalar que ésta no se encuentra en la plataforma a media ladera, sino inmediata a la cima de la sierra y en una zona hundida y con reducida visibilidad.

En las líneas de tránsito aparecen la mayor parte de las combinaciones circulares como motivo único y en menor medida cuadrúpedos (casi nunca cérvidos). Por lo tanto podemos introducir una segunda relación entre dichos petroglifos y lugares de paso.

Las entradas son lugares situados en los puntos de intersección entre los límites de la dispersión de los petroglifos y las líneas de tránsito. Aquí aparecen las representaciones de armas, generalmente espadas. Los petroglifos son: O Ramallal, Campo de Matabois y Pedra das Ferraduras. Por otro lado tenemos otros tres mucho más sencillos en los que aparece sólo un puñal y que se emplazan en zonas de transición entre los distintos grupos de petroglifos, es decir, entre As Canles y Chan do Salgueiriño y entre éste y Chan da Lagoa.

(11) De forma similar ya fue empleada esta división del espacio por B.K. Swartz y S. Hurlbutt (1994), que manejan los términos focus, entry y enclosure, inspirados en los estudios espaciales en arquitectura. 


\section{Las cruces inscritas}

Comentario aparte merecen los motivos de cruces inscritas en círculos (12), que creemos que no podemos incluir dentro del conjunto de petroglifos pertenecientes a la Edad del Bronce. Este motivo presenta una serie de características específicas:

1. En ocasiones tienen un surco más estrecho y con una pátina más viva.

2. Suelen aparecer en rocas con una amplia superficie y a ras del suelo.

3. Aunque en muchas ocasiones se ubican en las proximidades de petroglifos de la Edad del Bronce, en raras ocasiones comparten panel con éstos.

Las cruces inscritas, en términos generales, se concentran en la ladera del naciente del monte deAs Canles, situado en el centro de la estación en cuya cima han sido descubiertas dos inscripciones (13). También las encontramos en dos rocas de Chan da Lagoa, en una de Pedra da Escaleira, en Campo de Matabois y en las dos rocas de Monte do Calvo, donde aparecen asociadas a figuras escaleriformes.

\section{Estación de Tourón}

Perteneciente al sistema de Serra Castrelada, la estación de Tourón se encuentra rodeada por petroglifos situados en las laderas que la delimitan. Las rocas grabadas se sitúan próximas a las principales líneas de tránsito que desde el valle ascienden a la sierra. Dicha relación es reforzada por la circunstancia de que los zoomorfos aparecen orientadós en el misma dirección que las vías.

De forma sintética podemos dividir la distribución de los petroglifos en dos áreas bien diferenciadas, una superior con cérvidos y otra inferior con cuadrúpedos sin cornamenta. Si ordenamos los paneles por su grado de complejidad, tendremos los petroglifos más complejos situados en las zonas más altas y los más sencillos en las áreas bajas del terreno.

Respecto a la orientación de los zoomorfos volvemos a encontrar una distribución vertical. Se in-

(12) Hay que aclarar que más que cruces inscritas parecen representar círculos (en ocasiones cuadrados), subdivididos en cuatro sectores, pero por economía de lenguaje preferimos utilizar dicho término.

(13) Desde aquí queremos agradecer la colaboración del Prof. Dr. A. Rodríguez Colmenero. Dicho investigador sostiene que estas inscripciones puedan tratarse bien de una inscripción terminal, o de un término sacro, en cuyo caso podría tratarse de un adjetivo sustantivado o como adjetivo acompañado de un teónimo tácito (Santos et alii 1998). cide una vez más en la diferencia existente entre los petroglifos más complejos y los más sencillos. De este modo, mientras en los dos más complejos, Laxe das Cruces y Nabal do Martiño, las figuras zoomorfas se orientan en sentido descendente (a excepción de una minoría que lo hacen en sentido ascendente), los petroglifos situados a menor altitud tienen las figuras orientadas en sentido ascendente.

\section{La estación de A Ferradura: ¿un espacio diferente?}

Se localiza en el municipio deAmoeiro (Ourense) y fue descubierta durante el Proyecto de Control de Impacto Arqueológico de la Gasificación de Galicia. El relieve general es el de una zona llana en altura a modo de meseta y conocida como Chao de Amoeiro. La estación se sitúa en un rellano en el bórde del chao (o chan) en el inicio de la caída del escarpe hacia el fondo del valle del río Barbantiño (Fig. 11).

Esta estación presenta claras diferencias con las hasta ahora descritas tanto en lo referente a la tipología de los grabados como a la morfología del soporte. El tipo de petroglifos que encontramos en A Ferradura apenas ha sido estudiado, por esta razón desconocemos su adscripción cultural, aunque esto no nos impedirá realizar un estudio comparativo con las estaciones clásicas del occidente gallego (14).

Está formada por una treintena de rocas. En los extremos NE y $\mathrm{O}$ del chan de A Ferradura se hàllan dos castros de la Edad del Hierro Algo más de un $80 \%$ de las rocas grabadas tienen como motivo único las cazoletas, aunque también encontramos: herraduras, figuras cuadrangulares, cruces, círculos concéntricos e incluso una inscripción en Coto do Castro. El soporte más habitual son grandes batolitos, aunque también existen dos abrigos y alguna roca a nivel del suelo.

En términos generales podemos describir la estación ateniéndonos a tres elementos. Por un lado, en el extremo occidental está el castro de A Zarra, con grabados adscribibles a la Edad del Bronce, otro castro en el extremo nororiental con una inscripción y entre ellos un llano con un gran número de petroglifos instalados sobre grandes batolitos que destacan notablemente en el paisaje, no sólo por

(14) La estación de A Ferradura es muy similar a las descritas en Rodríguez (1977) en la provincia de Ourense y que el autor interpreta como posibles santuarios de la Edad dẹl Hiẹro.

T. P., 55, n. $^{\circ} 2,1998$ 


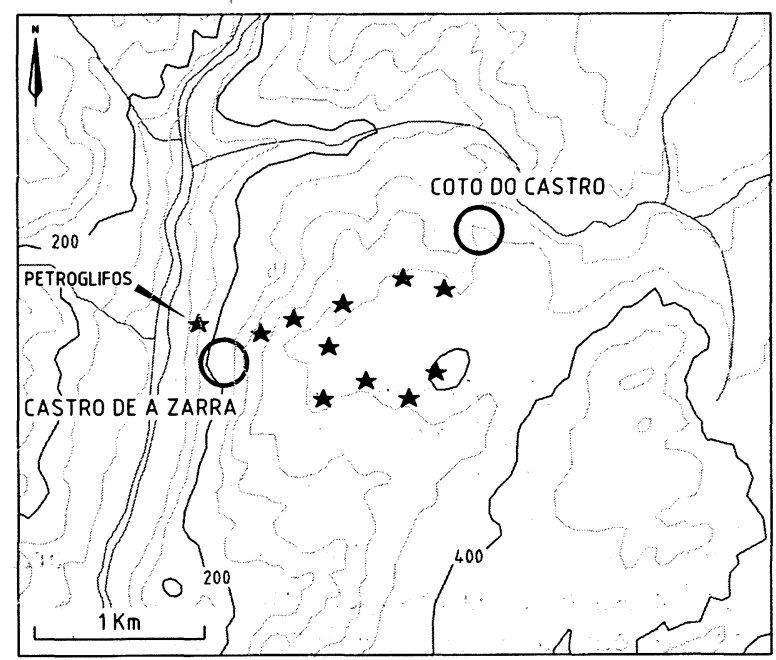

Fig. 11. Emplazamiento de la estación deA Ferradura en un rellano en torno al cual se encuentran dos castros, emplazamiento muy similar al del resto de las grandes estaciones.

su tamaño, sino también por su llamativa morfología a modo de piedräs flotantes.

En resumen nos encontramos ante una estación con petroglifos cuya monumentalidad le viene dada por el soporte y no por los grabados, ya que, al localizarse las cazoletas en la parte más alta de las rocas, muchas veces son invisibles para el observador que se encuentra a nivel del suelo.

Este tipo de estación recuerda a la localizada en Castro San Martiño en el ayuntamiento de Arbo (Pontevedra), donde también aparece una aglomeración rocosa con petroglifos con cazoletas, figuras cuadrangulares, herraduras y representaciones de huellas humanas, e incluso algún tablero de juego a modo de reticulado. Esta estación se encuentra en un asentamiento de la Edad del Hierro desde el que se divisa una amplia panorámica por hallarse en una plataforma a media ladera sobre el valle (Pérez y Santos, 1989).

\section{EL ESPACIO INTERNO DE LOS PANELES}

Como veremos, cada figura ocupa un lugar determinado en relación con el resto, respetando un esquema compositivo dentro de cada panel.

\section{Zona de Caneda}

Para ello aplicaremos el sistema de análisis propuesto en la introducción. El resultado es el que sigue:
Chan da Lagoa I A-B-C

Chan da Lagoa II EA-B

Pedra das Ferraduras AFBC-D

Laxe dos Cebros A-B

Coto do Rapadoiro AB-D

De los análisis de la organización de los paneles podemos extraer que:

- Las combinaciones circulares están por encima del resto de los motivos salvo las escenas de equitación.

- Las representaciones de cérvidos nunca aparecen por encima de los círculos.

- Las armas y los círculos aparecen por encima de los cérvidos.

- Los cuadrúpedos nunca aparecen por encima de los cérvidos

- Los antropomorfos nunca aparecen por encima de cualquier otro motivo.

El esquema que representaría el modelo organizativo ideal del espacio de los paneles sería: EAFB$\mathrm{CD}$, es decir, una escena de equitación en la parte superior (E), una combinación circular debajo (A), una arma debajo de ésta $(F)$, a continuación un cérvido (B), luego un cuadrúpedo sin cornamenta (C) y un antropomorfo en la parte más baja (D).

\section{Zona de Monte Arcela}

Los esquemas de distribución de los motivos en los paneles son los siguientes:

$\begin{array}{ll}\text { Laxe das Rodas } & \text { AB-C-E (15) } \\ \text { Lombo da Costa V } & \text { ABC } \\ \text { Lombo da Costa XV } & \text { AB } \\ \text { Laxe do Cuco } & \text { BCA } \\ \text { Fonte do Lagarto } & \text { A-B } \\ \text { Laxe das Coutadas } & \text { AB }\end{array}$

Las consecuencias que derivamos de los esquemas son las siguientes:

- Excepto en Laxe do Cuco, los círculos están por encima del resto de los motivos.

- Los cérvidos se sitúan bajơ los círculos y encima de los cuadrúpedos

De estas observaciones se puede extraer el ésquema $\mathrm{ABC}$ como modelo organizativo ideal del espacio interno de los petroglifos.

\section{Zona de Serra Castrelada}

Los esquemas de los paneles son los que siguen:

(15) Hay que aclarar que en este petroglifo existen tres cérvidos situados por encima de los círculos, pero la tendencia es clara al encontrar quince cuadrúpedos en una posición inferior. 
Laxe das Cruces

EABCD

Nabal do Martiño

$\mathrm{A}-\mathrm{B}-\mathrm{CD}$

Coto das Sombriñas VI

$\mathrm{ABC}$

Coto das Sombriñas IX

Coto das Sombriñas V

$\mathrm{ABCD}$

$\mathrm{CA}$

Respecto a la distribución de los motivos en los paneles, podemos extraer como consecuencias que:

- Los círculos concéntricos están por encima de todos los motivos excepto las escenas de equitación.

- Los ciervos están por debajo de los círculos.

- Los cuadrúpedos se sitúan por debajo de los ciervos.

- Los antropomorfos nunca están por encima de otro motivo.

El modelo esquemático es por lo tanto: EABCD.

\section{ANÁLISIS E INTERPRETACIÓN}

Analizaremos en conjunto las tres estaciones encuadrables en la Edad del Bronce y dejaremos para un apartado posterior un análisis comparativo con A Ferradura de cronología indeterminada. Detallaremos una serie de constantes que nos ayudarán a señalar los aspectos recurrentes que caracterizan a un paisaje con petroglifos.

\section{El panel: la representación del paisaje}

Observando la distribución de motivos, se ha definido un modelo de ordenación del espacio válido para todos los paneles de las estaciones estudiadas, ya que en las mismas se localizan al menos tres elementos comunes: combinaciones circulares, cérvidos y cuadrúpedos. Este modelo es el siguiente:

Las combinaciones circulares están a la misma altura o en una posición superior con respecto a los cérvidos y éstos se sitúan a la misma altura o en una posición superior con respecto a los cuadrúpedos sin cornamenta.

En el caso de la estación de Caneda, contamos con una mayor variedad de motivos, por lo que se puede ampliar la resolución del modelo de distribución que se cumple en todos los paneles de esta estación:

Las escenas de equitación se sitúan por encima del resto de los motivos, las combinaciones circulares están a la misma altura o por encima de las armas, las armas están por encima o a la misma altura que los cérvidos, los cérvidos están a la misma altura o por encima de los cuadrúpedos sin cornamenta y éstos están a la misma altura o por encima de los antropomorfos.
Por lo tanto obtenemos un modelo perfectamente compatible para las tres estaciones rupestres de la Edad del Bronce, donde los motivos que poseen en común mantienen el mismo orden:

\section{Caneda EAFBCD}

Monte Arcela ABC

Tourón EABCD

El esquema ideal de distribución de los motivos (EAFBCD) aplicable a cualquiera de los paneles estudiados se podría estructurar, basándonos en una serie de oposiciones, entre los motivos de la parte superior de los paneles y los motivos de la parte inferior. Así en la parte superior tendríamos las escenas de equitación, los combinaciones circulares, las armas y los cérvidos; y en la parte inferior los cuadrúpedos sin cornamenta y los antropomorfos. De aquí podemos definir los siguientes pares de oposiciones:

\begin{tabular}{|c|c|c|c|}
\hline $\begin{array}{l}\text { Parte } \\
\text { Superior }\end{array}$ & $\begin{array}{l}\text { Hombres } \\
\text { a caballo }\end{array}$ & Guerra & \\
\hline $\begin{array}{l}\text { Parte } \\
\text { Inferior }\end{array}$ & $\begin{array}{l}\text { Hombres } \\
\text { a pie }\end{array}$ & Pastoreo & \\
\hline $\begin{array}{l}\text { Parte } \\
\text { Superior }\end{array}$ & $\begin{array}{l}\text { Cuadrúpedos } \\
\text { con } \\
\text { cornamenta }\end{array}$ & Salvaje & $\begin{array}{l}\text { Adulto } \\
\text { (¿masculino?) }\end{array}$ \\
\hline $\begin{array}{l}\text { Parte } \\
\text { Inferior }\end{array}$ & $\begin{array}{l}\text { Cuadrúpedos } \\
\text { sin } \\
\text { cornamenta }\end{array}$ & Doméstico & $\begin{array}{l}\text { Joven } \\
\text { (¿femenino?) }\end{array}$ \\
\hline
\end{tabular}

\section{Las estaciones: la articulación del paisaje}

Analizaremos la distribución de los petroglifos dentro de cada estación teniendo en cuenta el grado de complejidad, el motivo de los paneles y la orientación de las figuras zoomorfas.

\section{Distribución de los motivos en la estación de Caneda}

Si observamos el mapa de los motivos más frecuentes (Fig. 7), podemos extraer las siguientes consideraciones:

Los petroglifos más complejos con armas se sitúan en los puntos de entrada al área de la estación, nos referimos a O Ramallal, Pedra das Ferraduras y Campo de Matabois en los extremos de la principal vía de tránsito. Por otro lado los petroglifos más sencillos se sitúan en puntos secundarios de entrada o bien de transición entre los escalones del relieve.

Los petroglifos con cérvidos están en torno a las dos brañas de Chan da Balboa y Chan da Lagoa. Generalmente aparecen en los paneles más com-

T. P., 55, n. ${ }^{\circ} 2,1998$ 
plejos y suelen asociarse a combinaciones circulares.

Los petroglifos con círculos concéntricos se sitúan a lo largo de las líneas de tránsito cuando son el único motivo grabado y en torno a brañas cuando se asocian a cérvidos.

Es necesario aclarar que en las anteriores líneas no se ha pretendido establecer una relación semántica directa entre los motivos y los lugares en los que se encuentran. Sería ingenuo pensar en una equivalencia entre zona llana y ciervo o entre círculo y lugar de paso. Aunque consideramos que debió existir alguna relación de otro tipo que, por el momento, desconocemos.

\section{Distribución de los motivos en Monte Arcela}

Los motivos más frecuentes son las combinaciones circulares, los cérvidos y los cuadrúpedos. Si bien las combinaciones circulares aparecen en todas las estaciones, las representaciones zoomorfas tienen una dispersión más restringida. Tras analizar la distribución de motivos en esta zona se extraen las siguientes observaciones:

- Los petroglifos más complejos se sitúan en la mitad oeste de Monte Arcela.

- Los cérvidos se sitúan en las estaciones más complejas.

- Las rocas de paneles más complejos se sitúan en lugares desde los que se divisa una amplia panorámica.

- En el extremo más oriental del sistema de estaciones de Monte Arcela, los petroglifos son sustituidos por túmulos.

Encontramos ciertos paralelismos entre Caneda y Monte Arcela en la ubicación de los petroglifos más complejos, ya que éstos suelen encontrarse en lugares desde los que se tiene un amplio dominio visual. Por otro lado, también observamos una relación entre petroglifos de la Edad del Bronce y túmulos, destacando la estación de Chan das Latas donde comparten el mismo emplazamiento en uno de los accesos al monte.

\section{Distribución de los motivos de Serra Castrelada}

Como se podrá comprobar, existen numerosas coincidencias entre el emplazamiento de los distintos motivos de las estaciones anteriores y las de Serra Castrelada:

- Los dos petroglifos más complejos, Laxe das Cruces y Nabal de Martiño, se sitúan en las lugares más altos y con mayor visibilidad y son los que contienen la casi totalidad de las representaciones de cérvidos.

- Cuanto más complejo y/o más alto está un petroglifo, los cérvidos son de mayor tamaño.

- Los paneles más sencillos se sitúan en las zonas más bajas.

- Las figuras de cuadrúpedos se orientan en sentido ascendente en relación a la pendiente de las laderas. En cambio los dos petroglifos monumentales y situados en la parte más alta, Nabal do Martiño y Laxe das Cruces, tienen la gran mayoría de los cuadrúpedos orientados en sentido descendente.

Podemos resumir que existen estrechos paralelismos en la forma de distribuir los petroglifos en las zonas de Serra Castrelada, Monte Arcela y Caneda, que nos permite hablar de una articulación del paisaje a partir de la diferente distribución de los cérvidos y los cuadrúpedos sin cornamenta. Al igual que en los paneles, volvemos a encontrar ciertajerarquización eśpacial entre las representaciones de animales salvajes y domésticos. Los cérvidos se localizan en lugares centrales en torno a las brañas o bien en lugares destacados y con una amplia visibilidad (esto ya es advertido en Bradley et alii, 1994), mientras que los cuadrúpedos sin cornamenta, cuando no comparten panel con cérvidos, están en lugares menos destacados o periféricos de las estaciones y más alejados de las brañas.

Una vez más los motivos, probablemente alusivos a la guerra, lo salvaje y a lo masculino ocupan los lugares más conspicuos. Mientras que los diseños referentes al mundo doméstico se instalan en lugares menos prominentes. Esta forma de ordenación del espacio entra en consonancia con un tipo de sociedad heroica donde se ensalzarían ciertos valores o cualidades atribuidas a un grupo social dominante constituido por guerreros. Esta estructura social se vería reflejada en el arte rupestre, tanto en los elementos representados como en la distribución de los mismos.

\section{Los sistemas de estaciones: la construcción del territorio}

En el apartado 2 habíamos visto como grupos de estaciones se situaban en las entradas a una sierra delimitando de este modo un posible territorio. Nos encontramos pues ante un emplazamiento de estaciones en la frontera entre dos paisajes que se podrían definir como opuestos o simétricos. Por un lado el paisaje tradicional donde población y campos de cultivo actuales se localizan en el valle; por 
encima de las aldeas está el terreno de monte, área de usos extensivos, que en el pasado se dedicaba al cultivo por sistema de rozas. Por el otro el paisaje de la Edad del Bronce, cuya descripción se hace a la inversa. Los lugares de habitación se encuentran en los altiplanos situados en las zonas altas del monte o en los rellanos a media ladera; luego tendríamos las laderas del monte que comunican los asentamientos con las tierras bajas del valle que suponemos deshabitadas (16).

En las áreas más extensamente prospectadas, Monte Arcela y Serra Castrelada, se ha podido definir un sistema formado por estaciones que circundan de este modo una unidad fisiográfica.. En su base y más concretamente en sus accesos, el espacio de la representación y en los altiplanos los asentamientos, como son los casos deVal da Porca para Monte Arcela y Portalaxa en Serra Castrelada.

El espacio de los petroglifos se ubica entonces en un punto liminal o de división entre el área de ocupación en la prehistoria reciente y el área que estaría desocupada. Este carácter de límite o de entrada a un supuesto territorio se ve resaltado por el hecho de que los paneles se hallan orientados hacia el exterior del territorio, es decir, orientados para ser vistos por el que entra o asciende hacia la sierra.

\section{Grandes estaciones y estaciones pequeñas}

Una vez analizado el emplazamiento general de los petroglifos, es necesario definir dos tipos de estaciones que se distinguen por su complejidad y por su emplazamiento. A modo de síntesis podríamos clasificar en:

Pequeñas Estaciones: Pueden situarse en rellanos o bien en puntos de paso a media ladera, siendo más característico este último emplazamiento. El número de petroglifos es reducido al igual que el repertorio de diseños. Se sitúan en puntos de paso o en ocasiones a lo largo de segmentos de las vías de tránsito, generalmente en la transición entre el valle y el monte.

Grandes estaciones: Se ubican rellanos a media ladera con una amplia visibilidad sobre el entor-

(16) La más que posible inexistencia de asentamientos de la Edad del Bronce en zonas de valle está avalada por el hecho de que la prospección intensiva de decenas de $\mathrm{km}^{2}$ y $1.300 \mathrm{~km}$. de obra lineal con remoción de tierra en la construcción del oleodúcto, gasoducto y autovías en Galicia, no ha permitido localizar asentamientos de la Edad del Bronce en fondo de valle. En todo caso tan sólo se conoce la existencia de necrópolis. El tema de la distribución de los asentamientos en la prehistoria reciente es estudiado por Criado (1988) no. Concentran un gran número de petroglifos, un amplio repertorio de motivos y paneles de gran complejidad (Laxe das Rodas, Laxe das Cruces, Laxe das Ferraduras o Nabal do Martiño). En el caso de Lombo da Costa, al igual que Chan da Lagoa o Chan da Balboa los petroglifos se disponen de forma circular en torno a un rellano.

El hecho de que los petroglifos se encuentren rodeando una braña ha sido interpretado en Bradley et alii (1994) como indicador de un área de reserva de pasto. De hecho en Serra do Bocelo, se ha definido un tipo de emplazamiento que vincula los asentamientos de la Edad del Bronce a cubetas con brañas (Méndez, 1994). Con todo, y matizando el pan-brañismo que últimamente acusa la arqueología gallega desde que se señaló por primera vez la significación de este elemento para comprender la localización de fenómenos arqueológicos, debemos destacar que no todas las brañas situadas en zonás de arte rupestre al aire libre se asocian a petroglifos. En la zona de Caneda, del total de tres brañas: Chan da Balboa en Fentáns, Chan da Lagoa en Parada y Chan do Salgueirón en la parte alta de la sierra, sólo las dos primeras se asocian. En Chan do Salguéirón, y a pesar de una intensa prospección, no se localizó ninguna roca grabada. En la zona de Monte Arcela, sólo una de las estaciones, Chan das Latas; se sitúa en las proximidades de una braña. En Serra Castrelada los grandes humedales están en los altiplanos de la sierra, donde no hay petroglifos y sólo en Tourón encontramos dos pequeñas brañas. Pero quizás uno de los casos más claros lo tengámos en la estación de Ámoedo, donde Santos (1996) definía un modelo de emplazamiento asociado a brañas. En esta estación podemos observar cómó śon las pequeños humedales situados a media ladera los que se asociaban a petroglifos; en cambio en la braña de Valongo, sin duda la de mayor extensión, no se ha localizado arte rupestre en su entorno cercano. ¿Cuál es pues la diferencia entre las brañas asociadas a petroglifos y las que no lo están?

Para responder a esta cuestión, podemos tomar como ejemplo la zona de Caneda. Mientras Chan do Salgueirón está en una área deprimida, rodeada de lomas que impiden verla a larga distancia, las brañas de Chan da Lagoa y Chan da Balboa, al situarse en rellanos a modo de "balcón" a media ladera, poseen un dominio visual bastante amplio. A esto se podría añadir que la visibilidad es especialmente amplia desde los petroglifos más complejos, como los dos principales de Chan da Lagoa y Pedra das

T. P., 55, n. ${ }^{\circ} 2,1998$ 
Ferraduras. Es el mismo tipo de emplazamiento que encontramos en el conjunto de Tourón o en Lombo da Costa, pero sin la presencia de brañas.

Con la información que nos aporta la interpretación del paisaje de las grandes estaciones, podemos deducir que la braña no siempre propicia la concentración de petroglifos, sino la existencia de una forma escalonada en el relieve, con una superficie más o menos amplia cuya localización le permite ser individualizada a distancia (Fig. 8) (17).

Podemos proponer como hipótesis de trabajo, la posibilidad de, al menos, una triple finalidad de los petroglifos. Por un lado, por su posición con respecto a las sierras donde se encuentran los asentamientos, pudieron servir de delimitadores de un territorio por el que se desplazarían las comunidades seminómadas vinculadas a éste. Otra posible finalidad sería la de apropiarse de zonas de reserva de pasto, que en momentos de sequía estival podría generar cierta competencia entre los distintas comunidades y más si tenemos en cuenta la posición periférica de estas brañas con respecto al territorio. Pero estos dos factores no explican la presencia de grandes concentraciones de arte rupestre en lugares donde no se detectan brañas o donde las brañas de mayor amplitud aparecen sin petroglifos, restringiéndose éstos a otros lugares. Por lo tanto como tercera finalidad para estas grandes estaciones, proponemos que pudieron servir de lugares de agregación o lugares de especial actividad ritual (18). Las razones son las siguientes:

- Se localizan en zonas llanas y amplias que permiten el encuentro de grupos humanos y el desarrollo de actividades intergrupales tales como intercambios, rituales, etc.

- Su emplazamiento posibilita su visibilidad e individualización en el paisaje desde largas distancias y por lo tanto desde asentamientos distantes.

- La ubicación en puntos liminales con respecto a los posibles territorios también favorecería su carácter de lugar de contacto entre distintas comunidades.

- La presencia, en ocasiones, de brañas o zonas de pasto favorece su condición de lugar de agregación de comunidades en las que la posesión de ganado pudo tener cierta importancia, no sólo en el plano económico, sino también como indicador de posición social.

(17) El emplazamiento en escalones tectónicos de los petroglifos ya es señalada por Vázquez (1995).

\section{A Ferradura como ejemplo de gran estación}

El emplazamiento deA Ferradura es muy semejante al de las definidas como grandes estaciones. Se localiza en un amplio rellano situado en una posición dominante sobre el valle. Esto le otorga una gran capacidad para ser divisado a larga distancia. Al igual que las estaciones de Caneda y Lombo da Costa, se sitúa en la ruptura de pendiente de un escarpe que domina un valle profundo. Pero si en el emplazamiento de ambos tipos de estaciones encontramos importantes similitudes, también existen notables diferencias en otros aspectos.

Las cazoletas son el motivo predominante, y sólo tres rocas en la estación de A Ferradura poseen combinaciones circulares. Los petroglifos en lugar de a ras del suelo, se instalan en grandes batolitos o en aglomeraciones rocosas que constituyen verdaderos monumentos naturales. Hay que destacar el petroglifo de O Cego (A Ferradura), que se sitúa en una pequeña roca a ras del suelo al pie de otra paralelipédica, modelada por la acción natural, pero cuya particular forma la convierte en un destacable hito en el paisaje.

Existe un clara preponderancia del soporte sobre loś grabados. Al contrario que en el área clásica, donde eran los grabados los que convertían al petroglifo en un monumento, en A Ferradura, son las propias rocas las que destacan en el paisaje, situándose las cazoletas, en la mayoría de los casos, en lugares poco visibles.

La similitud en lo referente al emplazamiento nos sugiere que sería posible atribuirles hipotéticamente una finalidad similar a la de las grandes estaciones de la zona occidental. Es decir, que independientemente de su cronología que con cierta cautela nos inclinamos a considerar la Edad del Hierro siguiendo la propuesta de Rodríguez Colmenero (1977), pudieron ser lugares de especial significación social.Aunque por el momento la base para tal hipótesis no sea aún muy sólida hay que tener en cuenta los factores ya referidos para las grandes estaciones de la zona occidental y que también son válidos para A Ferradura.

\section{CONCLUSIÓN}

A lo largo del desarrollo de este trabajo hemos visto como a tres escalas distintas de análisis se

(18) J.M.Vázquez (1990) apunta la posibilidad de que los grandes petroglifos de armas pudiesen ser lugares de agregación. 
definían una serie de modelos que estructuraban la distribución de los petroglifos en el paisaje y de los grabados en los paneles. Y cómo el emplazamiento es un factor esencial para comprender el espacio del arte rupestre.

En los paneles, definíamos una división entre posibles representaciones alusivas al mundo de lo doméstico que se situaba en la parte inferior del panel y lo alusivo al mundo de la guerra y a lo salvaje en la parte superior del panel. En el análisis del espacio interno de las estaciones veíamos como los petroglifos con cérvidos se situaban en las zonas centrales y/o elevadas de las estaciones y los petroglifos sin cérvidos en lugares menos destacados y periféricos de la estación. A su vez estudiando los conjuntos de estaciones, hemos definido dos sistemas muy similares, el de Serra Castrelada y Monte Arcela, vinculadas a los accesos a dos unidades fisiográficas que pudieron demarcar unidades territoriales en la Edad del Bronce.

\section{AGRADECIMIENTOS}

A Anxo Rodríguez (que confeccionó las figuras de este artículo), a Fidel Méndez y Cesar Parcero (representaciones digitales de mapas), a Felipe Criado (por prestarme sus ideas y conocimientos), a Paula Ballesteros, David Barreiro, Raquel López y Mercedes Rey.

\section{BIBLIOGRAFÍA}

Álvarez Núñez, A. (1985): "Los petroglifos de Fentáns (Cotobade)". Pontevedra Arqueológica, 2: 97-125.

Álvarez Núñez, A. y Velasco Souto, C. (1979): "Nuevas insculturas en Campo Lameiro". Gallaecia, 5: 17-72.

Bradley, R.; Criado Boado, F. y Fábregas Valcarce, R. (1994): "Los petroglifos gallegos como forma de apropiación del espacio: algunos ejemplos gallegos". Trabajos de Prehistoria, 51(2): 159-68.

- (1995): "Rock Art and the prehistoric landscape of Galicia: the results of field survey between 1992 and 1994". Proceedings of the Prehistoric Society, 61:347-70.

Criado Boado, F.(1988): "Arqueología del paisaje y espacio megalítico en Galicia”. Arqueología Espacial, 13: 61-117.
- (1994): "Límites y posibilidades de laArqueología del Paisaje”. SPAL, 2: 9-56.

Filgueira Valverde, J. y García Alén, A. (1953): Materiales para la carta arqueológica de la Provincia de Pontevedra. Museo de Pontevedra. Pontevedra.

Fraguas Fraguas, A. (1955): "Petroglifos del monte Pedreira en Carballedo (Pontevedra)". III Congreso $\mathrm{Na}$ cional de Arqueología (Zaragoza, 1955): 411-2.

García Alén, A. y Peña Santos, A.(1981): Los grabados rupestres de la provincia de Pontevedra. Fundación Barrié de la Maza. A Coruña.

MÉNDEZ FERnÁndeZ, F. (1991): "El campaniforme tardío: entre un pasado monumental y una cerámica conspicua". En F. Criado (dir.): Arqueología del Paisaje. El área Bocelo-Furelos entre los tiempos paleolíticos y los medievales. Arqueoloxía/Investigación, 6: 173-97. Santiago.

- (1994): "La domesticación del paisaje durante la Edad del Bronce gallego". Trabajos de Prehistoria, 51(1): 77-94.

Peña Santos, A. de la (1986): "Cuatro conjuntos de grabados rupestres en la feligresía de Tourón (Pontevedra)". Cuaderno de Estudios Gallegos, 36 (102):7-27.

Pérez Paredes, C.M. y Santos Estévez, M. (1989): "Gravados rupestres no concello de Arbo". Revista do Museo Municipal Quiñones de León de Vigo, 1-2: 51-80.

Rodríguez Colmenero, A. (1977): Galicia Meridional Romana. Universidad de Deusto. Bilbao.

Santos Estévez, M.(1996): "Los grabados rupestres de Tourón y Redondela-Pazos de Borbén como ejemplos de un paisaje con petroglifos". Minius, V: 13-40.

Santos Estévez, M.; Parcero Oubiña, C. y Criado Boado, F.(1998): "De la arqueología simbólica del paisaje a la arqueología de los paisajes sagrados": Trabajos de Prehistoria, 54(2): 61-80.

Sobrino Buhigas, R. (1935): Corpus Petroglyphorum Gallaeciae. Seminario de Estudios Galegos. Santiago de Compostela.

Swartz, B.K. y HulbutT, T.S.(1994): "Space, place and territory in rock art interpretation". Rock art research, 11, 1: 13-22.

VÁzquez Rozas, R. (1995): "Los petroglifos gallegos: selección de su emplazamiento y selección de las rocas grabadas". Actas del XXII Congreso Nacional de Arqueología (Vigo, 1993) I: 69-76. Vigo.

Vázquez Varela, J.M.(1990): Petroglifos de Galicia. Biblioteca de divulgación: Universidade de Santiago de Compostela. Santiago. 